\title{
Effect of siRNA targeting HER2/neu on the proliferation and viability of prostate cancer PC-3M cells
}

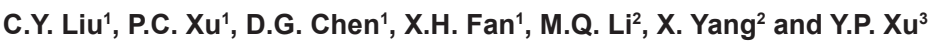 \\ 'Department of Urology, Lu'an Affiliated Hospital of Anhui Medical University, \\ Lu'an, China \\ ${ }^{2}$ Department of Urology, Fujian Medical University Union Hospital, Fuzhou, China \\ ${ }^{3}$ Institute of Urology, Zhejiang Cancer Hospital, Hangzhou, China \\ Corresponding author: P.C. Xu \\ E-mail: xupc2016@126.com
}

Genet. Mol. Res. 14 (4): 17145-17153 (2015)

Received August 24, 2015

Accepted October 29, 2015

Published December 16, 2015

DOI http://dx.doi.org/10.4238/2015.December.16.14

ABSTRACT. The aim of this study was to investigate the effect of a small interfering RNA (siRNA) targeting human epidermal growth factor receptor 2 (HER2/neu) on the proliferation and viability of prostate cancer PC-3M cells. Chemically synthesized siRNA targeting HER2/neu was transfected into PC-3M cells by using liposomes, and cells transfected with empty liposomes, a negative siRNA sequence, or nothing (untransfected) were used as controls. mRNA and protein levels of HER2/neu were detected using reverse transcription-polymerase chain reaction and western blot, respectively. The inhibitory action of HER2/neu siRNA on the in vitro growth of PC-3M cells was assessed by the cholecystokinin 8 assay and apoptosis was detected using flow cytometry. Cells transfected with HER2/neu siRNA showed decreased mRNA and protein levels of HER2/neu compared to control groups $(P<0.05)$. The survival rate of $P C-3 M$ cells decreased significantly after transfection with HER2/neu siRNA compared to that of untransfected cells $(55.39 \pm 1.60$ and $81.42 \pm 0.80 \%$, respectively; $\mathrm{P}<$ 0.05). The apoptosis rate in cells transfected with HER2/neu siRNA was 
quite high (45.60 $\pm 0.70 \%$ ) compared to that of blank control, empty liposome, and negative siRNA sequence groups $(P<0.05)$. In conclusion, siRNA targeting HER2/neu inhibits HER2/neu expression in PC-3M cells, resulting in an inhibition in proliferation and an induction of apoptosis.

Key words: Prostate cancer; RNA interference; HER2/neu; Small-interfering RNA

\section{INTRODUCTION}

Prostate cancer is the second leading cause of cancer death in men in North America (Boring et al.,1992). Recently, the incidence of prostate cancer has been rising in China and other Asian countries (Sim and Cheng, 2005). However, medication generally fails for androgenindependent prostate cancer, and new therapies are urgently required. The single-strand transmembrane protein, human epidermal growth factor receptor2 (HER2/neu), is localized to the q11-22 loci of human chromosome 17 and is aproto-oncogene. HER2/neu is highly expressed in breast cancer (Piccart-Gebhart et al., 2005), gastric cancer (Gravalos and Jimeno, 2008; Hofmann et al., 2008; Xie et al., 2009), endometrial carcinoma (Lukes et al., 2000), bladder cancer (Hansel et al., 2008), ovarian cancer (Steffensen et al., 2008; Vermeij et al., 2008), and prostate cancer (Signoretti et al., 2000). Overexpression of HER2/neu is associated with shortened survival, advanced recurrence, and poor prognosis in these cancers. We employed RNA interference (RNAi) to inhibit the expression of HER2/neu in prostate cancer PC-3M cells and examined the effect on the proliferation and viability of prostate cancer cells. These research findings provide potential new information for the development of new therapies for prostate cancer.

\section{MATERIAL AND METHODS}

\section{Materials}

Prostate cancer cell line PC-3M was donated by the Urology Surgery Center Laboratory, Fujian Medical University Union Hospital. RPMI1640 and fetal bovine serum (FBS) were purchased from Gibco (Los Angeles, CA, USA) and trypsin-EDTA was purchased from HyClone (USA). The rabbit anti-human HER2/neu primary antibody and Lipofectamine 2000 were from Invitrogen (USA). The reverse-transcription kit and PCR kit were purchased from Fermentas Inc. (USA), and the DNA molecular weight marker was purchased from Sangon Biotech (Shanghai, China). Primers were synthesized by Sangon Biotech, and siRNA-HER2/neu was synthesized by Biomics Biotechnologies Co., Ltd. (Nantong, China).

\section{Methods}

\section{Cell culture}

PC-3M cells were cultured conventionally and inoculated in a 6 -well plate $\left(5 \mathrm{X} 10^{5}\right.$ cells/ well). The cells were harvested for transfection when they showed good dispersion and grew to a density of about $70 \%$ after incubation at $37^{\circ} \mathrm{C}$ in a $5 \% \mathrm{CO}_{2}$ incubator for $16-24 \mathrm{~h}$. Cells were divided into four groups based on treatment condition: HER2/neu siRNA, empty liposome (Lipofectamine reagent with no siRNA), negative siRNA sequence, and blank control (untransfected). 


\section{Synthesis of siRNA-liposome complex}

Chemically synthesized siRNA was diluted in serum-free RPMI1640 and mixed well. Lipofectamine 2000 was also diluted in serum-free RPMI 1640 and incubated at room temperature for $5 \mathrm{~min}$. The siRNA was mixed with Lipofectamine 2000 and incubated at room temperature for 20 min to produce a siRNA-Lipofectamine 2000 complex.

\section{SiRNA transfection}

Negative control siRNA labeled with fluorescein (FAM) was transfected into the PC-3M cells according to the manufacturer protocol (Invitrogen, Shanghai, China). The efficiency of siRNA transfection was assessed by observation of the cells using a fluorescence microscope.

\section{Reverse transcription-polymerase chain reaction (RT-PCR)}

PC-3M cells entering the exponential growth phase were digested by $0.25 \%$ trypsin to form a suspension of single cells and the cell concentration was adjusted to $1 \mathrm{X} 10^{6} \mathrm{cells} / \mathrm{mL}$. The cells were inoculated on a 6 -well plate (5X $10^{5}$ cells/well) and cultured for $16 \mathrm{~h}$. When the cells were fully adherent to the well, transfection was performed. PC-3M cells were harvested $48 \mathrm{~h}$ after transfection. Total RNA extraction was carried out using TRIzol reagent (Sangon, Shanghai, China) according to the manufacturer protocol. Total RNA concentration and purity were detected with a UV spectrophotometer. Two-step RT-PCR was adopted using $\beta$-actin as an internal control. PCR conditions were 25 cycles of $94^{\circ} \mathrm{C}$ for $45 \mathrm{~s}, 57^{\circ} \mathrm{C}$ for $40 \mathrm{~s}$, and $72^{\circ} \mathrm{C}$ for $45 \mathrm{~s}$. A final extension step of $72^{\circ} \mathrm{C}$ was performed for $10 \mathrm{~min}$. All primers were designed using the Primer 3 software and synthesized by Sangon Biotech Co., Ltd. The primers for HER2/neu were as follows: forward 5'-CTCATCCACCATAACACC-3' and reverse 5'-TGGCTGCAGTTGACACACTGG-3'. PCR products were analyzed by $1.5 \%$ agarose gel electrophoresis, which was visualized and photographed under UV light. Semi-quantitative analysis was carried out with a video image analysis system (Bio-Rad, USA).

\section{Western blot}

The transfected PC-3M cells were harvested and treated with Pierce immunoprecipitation lysis buffer (Thermo Fisher, USA). Protein quantification was carried out using the BCA method. After SDS-PAGE, the protein bands were transferred to a NC-membrane and rabbit anti-human HER2/neu primary antibody (1:1000 dilution) was added. The cells were incubated overnightat $4^{\circ} \mathrm{C}$ while shaking, and the next day, horseradish peroxidase-labeled secondary antibody (goat antirabbit $\lg G$ ) was added following washing. After incubation at room temperature for $2 \mathrm{~h}$, the films were exposed, developed, and analyzed using Quality One software (Beijing, China). With $\beta$-actin as the internalcontrol, the expression of HER2/neu was calculated using densitometry.

\section{Effect of silenced HER2/neu gene on the growth of prostate cancer cells}

PC-3M cells reaching the exponential growth phase were digested with trypsin to form a suspension of single cells. The cells were inoculated on a 96 -well plate ( $N=5$ for each treatment). The cells were cultured at $37^{\circ} \mathrm{C}$ in a $5 \% \mathrm{CO}_{2}$ incubator for $24 \mathrm{~h}$, with culture medium containing no 
cells as the blank control. Seventy-two hours after transfection, $15 \mu \mathrm{L}$ cholecystokinin 8 (CCK8) reagent (Shanghai, China) was added into each well and incubated for another $4 \mathrm{~h}$. Optical density at 450nm [D(450)] was measured with a microplate reader. Survival rate of cells was calculated as [mean experimental $\mathrm{D}(450)]$ / [mean control $\mathrm{D}(450)] \times 100 \%(\mathrm{~N}=5)$.

\section{Flow cytometry for detecting cell apoptosis}

PC-3M cells were harvested and digested $72 \mathrm{~h}$ after transfection. The cells were washed twice with PBS, and $5 \times 10^{5}$ cells were suspended in $500 \mu \mathrm{L}$ binding buffer (Biotech, Beijing, China). Annexin V-FITC $(5 \mu \mathrm{L})$ and propidium iodide (PI, $5 \mu \mathrm{L})$ (Biotool, Chicago, IL, USA) were added successively to the cell suspension followed by incubation of the cells at room temperature for 10 min in the dark. Cell apoptosis was detected using flow cytometry (FC001).

\section{Statistical analysis}

The data are reported as mean \pm standard deviation, and statistical analysis was performed using SPSS17.0 software(USA). The Student $t$-test was used for two-sample comparison, and one-way ANOVA for multi-sample comparison.

\section{RESULTS}

\section{siRNA transfection}

PC-3M cells transfected with FAM-labeled negative control siRNA were observed under the fluorescence microscope. FAM-labeled siRNAs were evenly distributed in the cells, with transfection efficiency reaching over $80 \%$ (Figure 1).

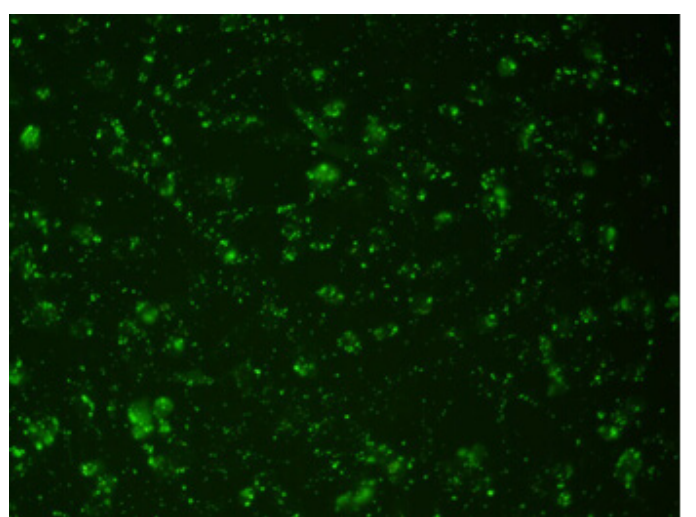

Figure 1. Fluorescence microscopy of PC-3M cells transfected with FAM-labeled siRNA for $24 \mathrm{~h}$ (200X magnification).

\section{HER2/neu gene expression}

Total RNA was extracted from PC-3M cells $72 \mathrm{~h}$ after transfection. Levels of HER2/neu mRNA were detected for each group using RT-PCR. The results of agarose gel electrophoresis 
indicated that mRNA levels of HER2/neu were down in PC-3M cells treated with HER2/neu siRNA $(0.25 \pm 0.03)$ compared to the blank control $(0.75 \pm 0.02)$, empty liposome $(0.72 \pm 0.03)$, and negative siRNA sequence groups $(0.70 \pm 0.02)(P<0.05)$. The differences were not significant between the blank control, empty liposome, and negative siRNA sequence groups (Figure 2, P > 0.05).

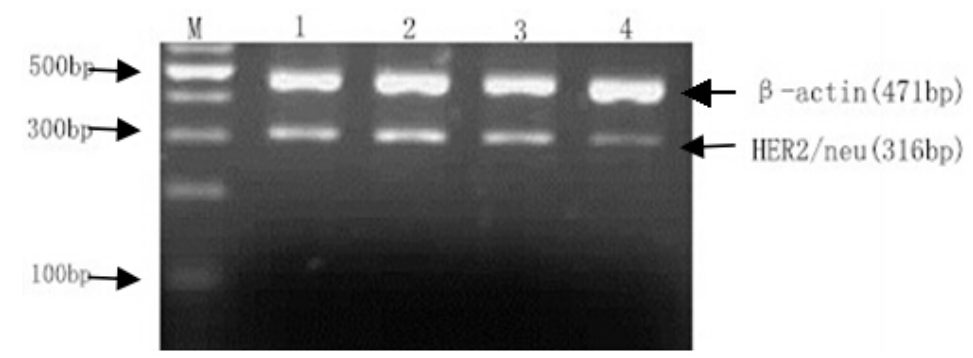

Figure 2. Agarose gel showing mRNA levels of HER2/neu and $\beta$-actin in PC-3M cells. Lane $M=$ standard; lane $1=$ blank control; lane 2 = empty liposomes; lane 3 = negative siRNA sequence; lane 4 = HER2/neu siRNA.

\section{Detection of HER2/neu by western blot}

Total protein was extracted from the PC-3M cells $72 \mathrm{~h}$ after transfection and analyzed by western blot. Results showed that the relative expression of HER2/neu in the negative siRNA sequence group, empty liposome group, and blank control group was $74.28 \pm 0.01,75.86 \pm 0.02$ and $77.59 \pm 0.01 \%$, respectively (expression was normalized to $\beta$-actin). Protein expression of HER2/neu in the empty liposome and negative siRNA sequence groups were not significantly different from the blank control group $(P>0.05)$. The relative expression of HER2/neu in the HER2/neu siRNA group was $46.83 \pm 0.02 \%$, which is significantly lower than thatin the other groups $(P<0.05)$. Therefore, a siRNA targeting HER2/neu effectively inhibited protein expression of HER2/neu (Figure 3).

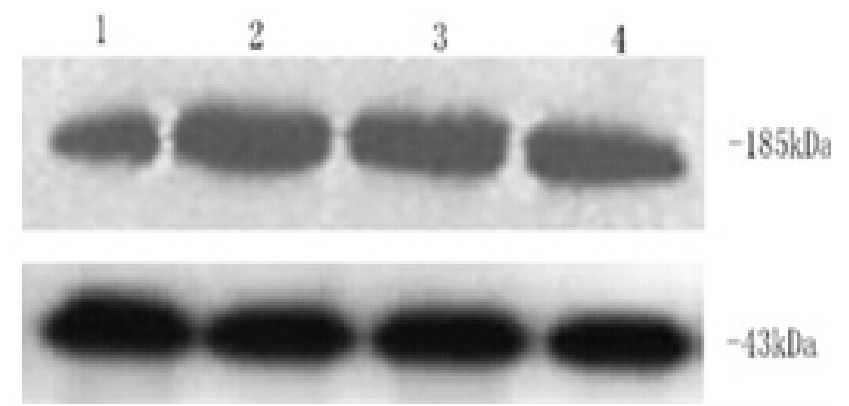

Figure 3. Western blot showing protein expression of HER2/neu and $\beta$-actin in PC-3M cells after transfection. Lane 1 = HER2/neu siRNA; lane 2 = negative siRNA sequence; lane 3 = empty liposomes; lane 4 = blank control.

\section{Effect of HER2/neu siRNA on the growth of prostate cancer PC-3M cells}

The CCK8 assay revealed that the survival rate of $\mathrm{PC}-3 \mathrm{M}$ cells in the empty liposome, negative siRNA sequence, and HER2/neu siRNA groups was $79.59 \pm 2.00,81.42 \pm 0.80$ and $55.39 \pm 1.60 \%$, respectively. No significant difference was observed in survival rate between the empty liposome and negative siRNA sequence groups $(P>0.05)$, but the survival rate of $P C-3 M$ 
cells transfected with HER2/neu siRNA was significantly lower than those transfected with empty liposomes or negative siRNA sequence $(P<0.05)$.

\section{Effect of HER2/neu siRNA transfection on the apoptosis of prostate cancer PC-3M cells}

The apoptosis rate of PC-3M cells in the blank control, empty liposome, and negative siRNA sequence groups was $3.87 \pm 0.30,5.50 \pm 0.36$ and $5.33 \pm 0.51 \%$, respectively. Seventy-two hours after HER2/neu siRNA transfection, the apoptosis rate of PC-3M cells was $45.60 \pm 0.70 \%$, which is significantly higher than the rates of the other three groups $(P<0.05)$. This indicates that knockdown of HER2/neu induced cancer cell apoptosis (Figure 4).
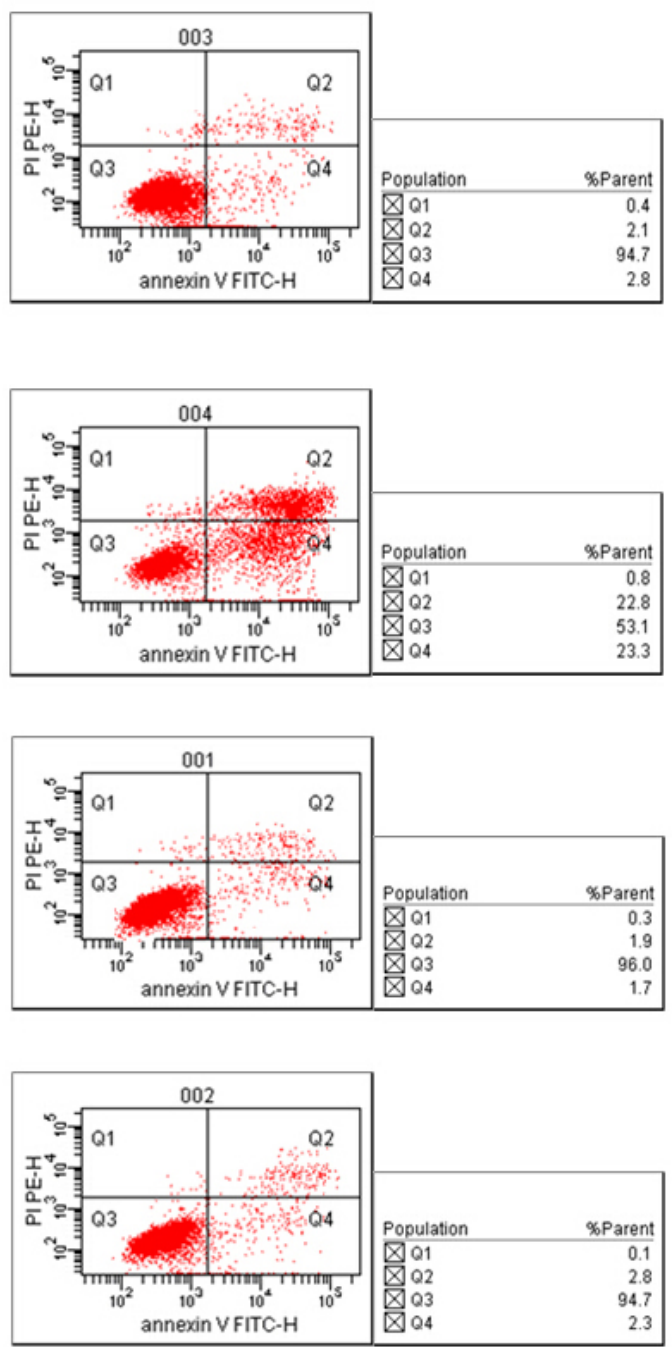

Figure 4. Flow cytometry instrument to detect cell apoptosis. 


\section{DISCUSSION}

RNAi or post-transcriptional gene silencing (PTGS) is a sequence-specific phenomenon mediated by double-stranded RNA (dsRNA) and is widely present in nature. Elbashir et al. (2001) demonstrated that dsRNA induced specific RNAi in mammalian cells without causing nonspecific interferon response. RNAi has several attractive features compared with reverse genetic techniques, which has resulted in its widespread use (Hu et al., 2002; Jacque et al., 2002). Firstly, RNAi is specific, as it only degrades mRNA of homologous genes, and asingle base change can greatly affect targeting and inhibition. Second, the high efficiency of RNAi allows the expression of a target gene to be reduced to a very low level even when the concentration of RNAi delivered is lower than that of antisense nucleic acids by several orders of magnitude. Lastly, the diffusibility of RNAi allows it to spread from the acting site of dsRNA and penetrate the cellular barrier in simple organisms; in fact, it is even passed down to offspring. At present, RNAi has become a novel genedisruption technique that silences or inhibits the expression of the target gene. This technique is widely used for new gene screening, identification of gene function and gene therapy.

As a proto-oncogene, HER2/neu is generally inactivated under normal conditions. HER2/ neu is overexpressed in $20-40 \%$ of human cancers and shows a close correlation with shortened survival (Hicks and Kulkarni, 2008; Sun et al., 2009). Cancer cells overexpressing HER2/neu are less sensitive to chemotherapy and correlate with a poor prognosis in patients. Furthermore, HER2/ neu promotes the proliferation and differentiation of cancer cells. E26 transformation-specific (ETS) transcription factor ER81 is activated by the Ras/MAPK pathway and binds to the ETS site of the human telomerase reverse transcriptase (hTERT) promoter region. By upregulating hTERT transcription, the telomerase is expressed abnormally and cells enter a permanently proliferative state (Goueli and Janknecht, 2004). HER2/neu inhibits cell apoptosis and facilitates cell cycle progression via the phosphoinositide 3-kinase (PI3K)/Akt pathway. Activation of PI3K can prevent the formation of the $\mathrm{Bcl}-\mathrm{XL}$ complex from Bad and the anti-apoptotic $\mathrm{Bcl}-2$ protein, thereby inhibiting the expression of pro-apoptotic genes and activating the Smad7 promoter. The inhibitory effect of transforming growth factor (TGF)- $\beta 1$ on cell proliferation can be suppressed by Smad7 binding to the TGF- $\beta 1$ receptor. Smad7 overexpression may also facilitate evasion of antigrowth signals and apoptosis (Dowdy et al., 2003). HER2/neu is also involved in tumor infiltration. Through secretion of matrix metalloproteinases (MMPs), HER2/neu can cause the translocation or metastasis of cancer cells and promote tumor infiltration and/or metastasis.

Studies using immunohistochemistry methods to detect HER2/neu protein expression in prostate cancer cells have produced inconsistent results, with positive rates varying from 0 to $100 \%$ (Ross et al.,1997). This may be attributed to differences in specimens, reagents, and interpretation of positive results. Shi et al. (2001) examined specimens from 81 patients with prostate cancer, including 31 stage $\mathrm{C}$ patients receiving no preoperative treatment, 30 stage $\mathrm{C}$ patients receiving preoperative androgen-deprivation therapy and 20 patients with androgen-independent prostate cancer, and the number of HER2/neu positive cases was $9(19 \%), 15(50 \%)$, and $17(85 \%)$, respectively. Montironi et al. (2006) studied the overexpression of HER2/neuin prostate cancer. In prostate cancer samples from patients receiving no hormone therapy, receiving hormone therapy, or with androgen-independent prostate cancer, 36, 47.5, and 78\% showed overexpression of HER2/neu, respectively. As shown by the data above, HER2/neu is overexpressed in prostate cancer cells, particularly in those patients receiving androgen-deprivation therapy and having androgen-independent prostate cancer (Wang et al., 2009). It is inferred that HER2/neu protein overexpression may be involved in the progression of androgen-dependent prostate cancer into 
androgen-independent prostate cancer. Therefore, HER2/neu overexpression can be used as a predictor of the risk of prostate cancer progression and recurrence.

We employed RNAi transfection to downregulate HER2/neu in prostate cancer PC$3 \mathrm{M}$ cells. The results indicate that HER2/neu siRNA decreased HER2/neu mRNA and protein levels in PC-3M cells compared to controls $(P<0.05)$. No significant differences were found in HER2/neu protein levels in all three control groups (blank control, empty liposome, and negative siRNA sequence group; $P>0.05$ ). This indicates that HER2/neu siRNA has excellent specificity. Moreover, after transfection with HER2/neu siRNA, the survival rate of the PC-3M cells decreased and apoptosis was induced $(20 \%$ decrease in survival and $40 \%$ increase in apoptosis compared to controls). This suggests that HER2/neu siRNA can successfully target and impede growth of cancer cells positive for HER2/neu.

Some studies have used HER2/neu monoclonal antibodies in the treatment of prostate cancer, but satisfactory outcomes were never achieved. The reason for this may be different therapeutic dosages are required compared to other cancers, or variation in the role of HER2/neu in the occurrence and progression of prostate cancer (Kuhn et al., 1993; Morris et al., 2002). HER2/ neu siRNA has proven to be effective in inhibiting the proliferation and inducing the apoptosis of PC-3M cells, presumably via the downregulation of HER2/neu mRNA and protein. This study reports that downregulation of HER2/neu using siRNA can be potentially applied in the treatment of prostate cancer, particularly androgen-independent prostate cancer. However, the in vivo effects of HER2/neu siRNA on HER2/neu gene/protein expressionand prostate cancer cell proliferation and apoptosis remain to be further investigated.

\section{Conflicts of interest}

The authors declare no conflict of interest.

\section{REFERENCES}

Boring CC, Squires TS and Tong T (1992). Cancer statistics,1992. CA Cancer J. Clin. 42: 19-38.

Dowdy SC, Mariani A and Janknecht R (2003). HER2/neu and TAK1-mediated up-regulation of the transforming growth factor beta inhibitor Smad7 via the ETS protein ER81. J. Biol. Chem. 278: 44377-44384.

Elbashir SM, Lendeckel W, Tuschl T, Yalcin A, et al. (2001). Duplexes of 21-nucleotide RNAs mediate RNA interference in cultured mammalian cells. Nature 411: 428-429.

Goueli BS and Janknecht R (2004). Upregulation of the catalytic telomerase subunit by the transcription factor ER81 and oncogenic HER2/neu, Ras, or Raf. Mol. Cell. Biol. 24: 25-35.

Gravalos C and Jimeno A (2008). HER 2 in gastric cancer: a new prognostic factor and a novel therapeutic target. Ann. Oncol. 19: $1523-1529$

Hansel DE, Swain E, Dreicer R and Tubbs RR (2008). HER2 overexpression and amplification in urothelial carcinoma of the bladder is associated with MYC coamplification in a subset of cases. Am. J. Clin. Pathol. 130: 274-281.

Hicks DG and Kulkarni S (2008). HER2 breast cancer: review of biologic relevance and optimal use of diagnostic tools. Am. J. Clin. Pathol. 129: 263-273.

Hofmann M, Stoss O, Shi D, Büttner R, et al. (2008). Assessment of a Her2 scoring system for gastric cancer: results from a validation study. Histopathology 52: 797-805.

Hu W, Myers C, Kilzer J, Pfaff SL, et al. (2002). Inhibition of retroviral pathogenesis by RNA interference. Curr. Biol. 12: $1301-1311$. Jacque JM, Triques K and Stevenson M (2002). Modulation of HIV-1 replication by RNA interference. Nature 418: $435-438$.

Kuhn EJ, Kurnot RA, Sesterhenn IA, Chang EH, et al. (1993). Expression of the c-erbB-2 (HER2/neu) oncoprotein in human prostatic carcinoma. J. Urol. 150: 1427-1433.

Lukes AS, Kohler MF, Pieper CF, Kerns BJ, et al. (2000). Multivariable analysis of DNA ploidy, p53, and HER2/neu as prognostic factors in endometrial cancer. Cancer 73: 2380-2385. 
Montironi R, Mazzucchelli R, Barbisan F, Stramazzotti D, et al. (2006). HER2 expression and gene amplification in PT2a Gleason score 6 prostate cancer incidentally detected in cystoprostatectomies: comparison with clinically detected androgen-dependent and androgen-independent cancer. Hum. Pathol. 37: 1137-1144.

Morris MJ, Reuter VE, Kelly WK, Slovin SF, et al. (2002). HER2 profiling and targeting in prostate carcinoma. Cancer 94: $980-986$.

Piccart-Gebhart MJ, Procter M, Leyland-Jones B, Goldhirsch A, et al. (2005). Trastuzumab after adjuvant chemotherapy in HER2/neu-positive breast cancer. N. Engl. J. Med. 353: 1659-1672.

Ross JS, Sheehan CE, Hayner-Buchan AM, Ambros RA, et al. (1997). Prognostic significance of HER2/neu gene amplification status by fluorescence in situ hybridization of prostate carcinoma. Cancer 79: 2162-2170.

Shi Y, Brands FH, Chatterjee S, Feng AC, et al. (2001). HER2/neu expression in prostate cancer:high level of expression associated with exposure to hormone therapy and androgen independent disease. J. Urol. 166: 1514-1519.

Signoretti S, Montimni R, Manola J, Altimari A, et al. (2000). Her2/neu expression and progression toward androgen independence in human prostate cancer. J. Natl. Cancer Inst. 92: 1918-1925.

Sim HG and Cheng CW (2005). Changing demography of prostate cancer in Asia. Eur. J. Cancer 41: 834-845.

Steffensen KD, Waldstrom M, Andersen RF, Olsen DA, et al. (2008). Protein levels and gene expressions of the epidermal growth factor receptors, HER1, HER2, HER3 and HER4 in benign and malignant ovarian tumors. Int. J. Oncol. 33: $195-204$.

Sun M, Behrens C, Feng L, Ozburn N, et al. (2009). HER family receptor abnormalities in lung cancer brain metastases and corresponding primary tumors. Clin. Cancer Res. 15: 4829-483.

Vermeij J, Teugels E, Bourgain C, Xiangming J, et al. (2008). Genomic activation of the EGFR and HER2-neu genes in a significant proportion of invasive epithelial ovarian cancers. BMC Cancer 8: 3.

Wang LF, Zhou Y, Xu YM, Qu XC, et al. (2009). A caspase-6 and anti-HER2 antibody chimeric tumor-targeted proapoptotic molecule decreased metastasis of human osteosarcoma. Cancer Invest. 27: 774-780.

Xie SD, Xu CY, Shen JG, Jiang ZN, et al. (2009). HER 2/neu protein expression in gastric cancer is associated with poor survival. Mol. Med. Rep. 2: 943-946. 